\title{
SUPPLY AND DEMAND ANALYSIS OF A FREE FLOATING BIKE SHARING SYSTEM
}

Cristian Poliziani**, Joerg Schweizer, Federico Rupi

Department of Civil, Chemical, Environmental and Materials Engineering, University of Bologna, Italy

*E-mail of corresponding author: cristian.poliziani2@unibo.it

\section{Resume}

This article presents an analysis of the supply and demand of a FFBSS recently implemented in the city of Bologna, Italy. The main aspects treated in this paper are: analysis of bike availability; temporal analysis of FFBSS demand; calibration and validation of a novel model that predicts the number of daily trips per available bike. This model is based on a linear combination of several day attributes, including meteorological and day-type attributes. Moreover, an origin to destination analysis is generated showing the spatial distribution of FFBSS trips. The methods are applied to a scenario with almost a million GPS traces recorded between July and October 2018 by the FFBSS in Bologna. Findings could support FFBSS companies to better understand the fluctuation of both the transport demand and supply of this relatively recent transport mode, as to make more efficient decisions when distributing or relocating bicycles.

Available online: https://doi.org/10.26552/com.C.2022.2.A53-A65

\section{Article info}

Received 30 September 2021

Accepted 16 November 2021

Online 20 January 2022

\section{Keywords:}

bike sharing

free floating

demand prediction

GPS traces

bike re-allocation

\section{Introduction}

Congestion problems in urban centers, together with the issue of environmental sustainability, has led the European Union to develop regulations aimed at development of efficient and sustainable urban mobility system. Several studies show that cycling mobility has significantly increased in recent years [1-4], thus taking a pivotal role in the transition to an economically feasible, socially acceptable and environmentally friendly urban mobility. In this context, bike-sharing services represent organic and efficient systems, which offer both an alternative and an integration with more classic modes of transport. Bike-sharing systems are continuously evolving since the late nineties, starting from station-based bike sharing system up to the recent free-floating bike-sharing system (FFBSS). This latter allows users to borrow and return bikes everywhere and at any time within the area of service coverage. The bikes are located with a geo referenced map on a smartphone application through which users can pay their own trips. The FFBSS allows a high spatial and temporal flexibility. Three particularly useful FFBSS characteristics for clients are: 1) they do not need to own and maintain a bicycle; 2) they are not forced to make a round trip, or to return the bike at the same pick-up point and this is particularly important in the case of unpredicted adverse meteorological conditions; 3) they do not have to worry about bike-theft or vandalism. One main problem of the FFBSS, which is also one of the main contribution to operating cost, is the bike reallocation problem: bikes tend to concentrate in different area, leading to a demand-dissatisfaction [5-8]. Some static [7-8] or dynamic [5, 9] reallocation methodologies are proposed in literature. For example, reallocation needs are structured by clustering zones with similar bike-availability [5]. However, the main issue for freefloating bike-sharing system is that reallocation models require the demand-pattern in order to predict where to reposition bikes [10-11] - an issue not yet widely studied in literature. This is in contrast with the stationbased bike sharing system where many reallocation methods have been proposed and studied [10, 12-15]. For example, Chen et al. [16] have tried to predict the gap between the inflow and outflow of bike trips in a certain time-interval and zone by analyzing land-use, weather and air-quality data. Pan et al. [15], propose a real-time method for predicting bike-sharing renting and returning in different areas of a city during a future period based on historical data, weather data and time data. Therefore, reallocation models need to know how many bikes should be re-allocated, from where to where and the reallocation strategy (optimal path), in order to increase both the service usage and the user satisfaction [17] and to decrease the operating costs. An interesting alternative to the bike re-allocate strategy has been examined by Pfrommer et al. [18] and Fricker and Gast [6]: it consists of incentive policies aimed at encouraging users to return bikes where needed. Another FFBSS problem could be the absence of a dedicated cycling 
infrastructure [19] and the presence of faulty bikes [2021 ], which not only represents a negative impact on the company's balance sheet, but also causes safety concerns, complicates the repositioning strategy and reduces the number of available bikes. In addition, the stolen as well as vandalized bikes clearly represent a not-negligible costs' component [22]. Moreover, a poorly designed FFBS system, e.g. in terms of recommended parking lots, or without providing discount for the correct bikeusage, could lead to higher travel-costs for the user and discourage the use of the service [23]. However, these problems of the bike-sharing system are not yet widely studied in literature and to date no FFBSS demand model has been studied in detail.

The paper focuses on a spatial and temporal analysis of the FFBS system; apart from a temporal and spatial descriptive analysis of the FFBSS trips, the core of the paper represents a prediction model of the FFBSS demand in terms of average number of daily trips per available-bike for different day types.

As for the model-calibration, the bike-availability pattern must be known and this is investigated in this paper.

The prediction model would allow a better comprehension of the FFBSS demand fluctuation for different days in a certain city. In addition, the model would allow to predict the FFBSS demand for the following day according to the day-type attributes and weather conditions. Such predictions are particularly useful for the scheduling of the bike re-allocation. These attributes were also used by Wafic et al. [24] to analyze the travel demand of bike sharing systems. Furthermore, a spatial analysis aims at identifying the most dominant traffic zones involved in FFBSS trips, which improves relocating bikes major points of attraction or generation.

As data from other cities will be available, then future studies could test the transferability of the proposed model - this model does have the potential to be generalized to other locations, as it requires data for calibration that is either publicly accessible or that could be made available by the FFBSS service provider.

The analysis is applied to the city of Bologna by using the software SUMOPy [25], developed by the University of Bologna. SUMOPy is a software extension of the traffic simulator SUMO [26] that contains a dedicated plugin for the GPS traces analysis already used and tested, as reported in other studies [27-28].

The GPS traces have been collected by the FFBSS service provider, Mobike [29], from July to October 2018. Generally, a GPS trace is composed of a series of the GPS points with both spatial and temporal coordinates. From these coordinates it is possible to identify the traveled road and even to extrapolate the speed profile [30-31]. Unfortunately, for this study only the start and end-points of trips have been provided; however, the used data set counts almost a million trips, which is considerably more than the amount of trips analyzed in similar studies [32-33].

The paper is organized as follows: section 2 describes the study area and the features of the bike network. In

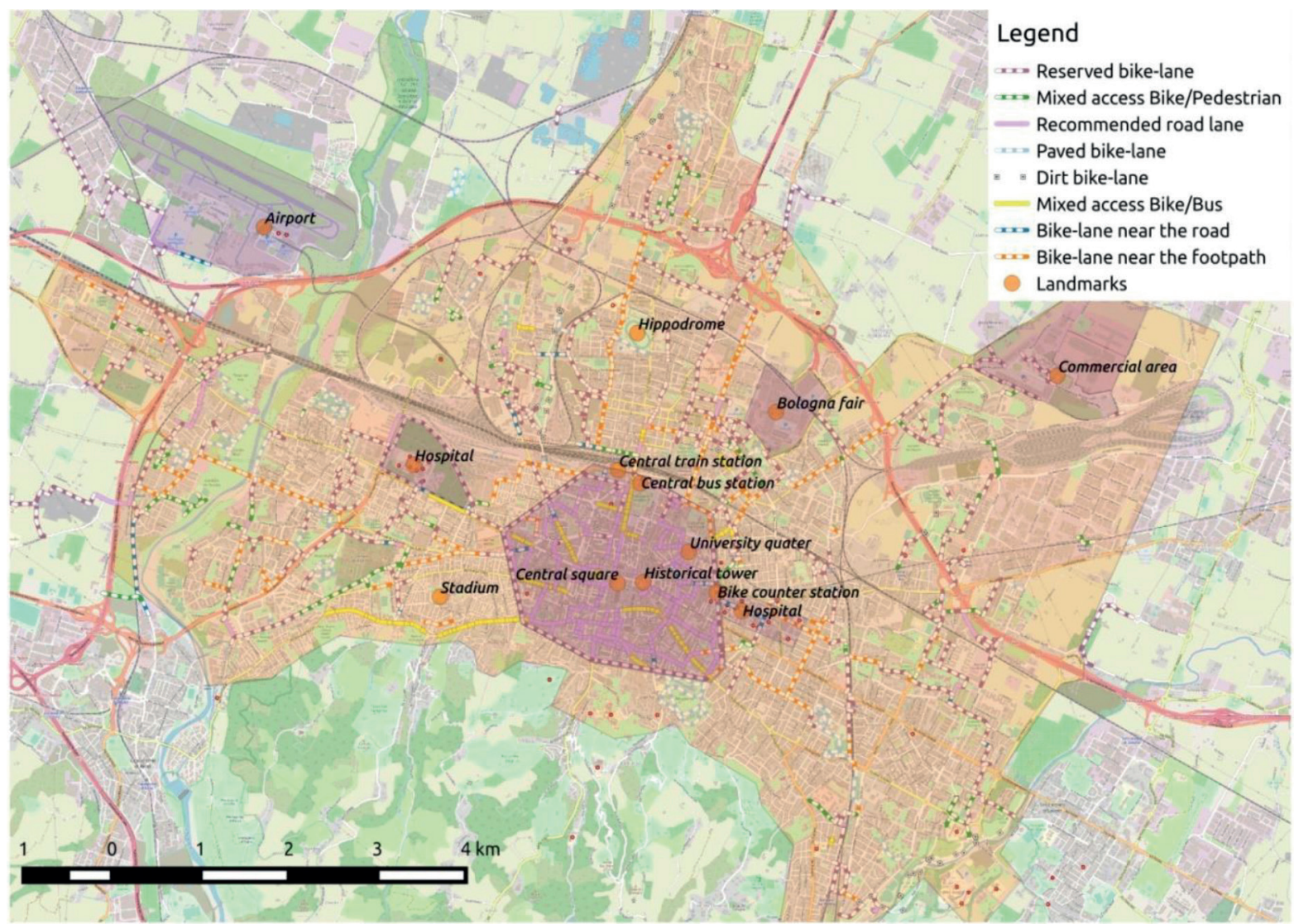

Figure 1 Study area with more important landmarks and the Mobike cover area, highlighted in orange 
section 3 , the data preparation process is described. Section 4 analyses the bike availability problem, section 5 shows a temporal analysis of the FFBSS demand and section 6 describes the new predictive FFBSS demand model. Section 7 shows a spatial analysis of the FFBSS demand. Conclusions and future research directions are presented in section 8 .

\section{Study area}

Bologna is a northern Italian city with approximately 390,000 inhabitants. The climate is convenient for cycling all year, with an annual average temperature slightly below $15^{\circ} \mathrm{C}$ and low rainfall (about $700 \mathrm{~mm}$ rain/ year and 74 days of rain per year). Bicycle flows have constantly grown in recent years in Bologna, along with an increasing bikeway supply [3]. Currently, there are $129 \mathrm{~km}$ bikeways of different types in the city (see Figure 1): 1) reserved bike lanes; 2) mixed access bike lanes with either pedestrian or buses; 3 ) bike lanes placed side by side to either footpaths or road; 4) dirt bike lanes; 5) recommended roads in the city center, only where there are no bike lanes; 6) paved bike-lanes inside city parks. Figure 1 indicates also the main city land-marks and the area covered by the Mobike FFBSS $\left(73 \mathrm{~km}^{2}\right)$.

\section{Data preparation}

The available GPS data includes all the FFBSS trips in Bologna from the $1^{\text {st }}$ July 2018 to the $31^{\text {th }}$ October 2018, collected by the Mobike company. These data are referred to the first four months of Mobike's activity in the city of Bologna: Mobike was the first and only FFBSS service in Bologna during the study period. This service progressively provided 2,200 bikes called "Mobike Lite" by the end of 2018. Data were provided by society SRM (Societa Reti di Mobilita [34]) and consist of almost one million trips recorded directly by the GPS device on each bike. This device does record the GPS trace of each trip as a sequence of geo-referenced points

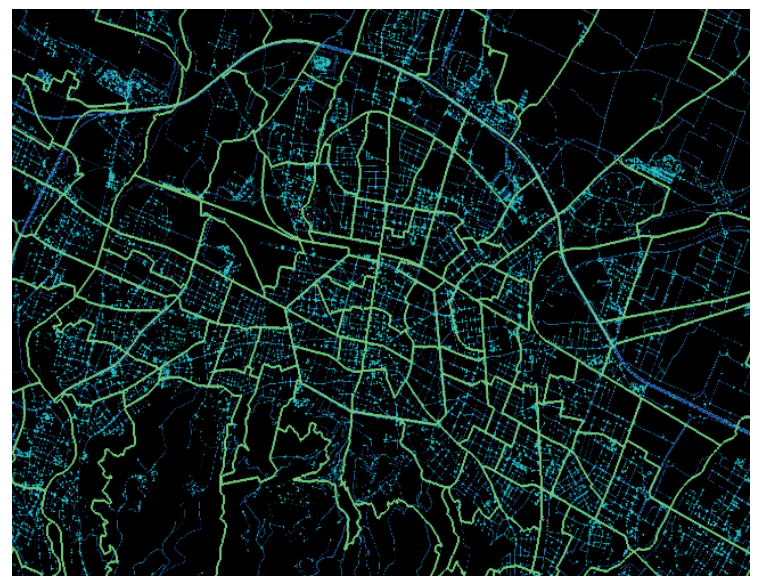

(a) with time stamps. However, for the present study, only the bike ID and the first and the last GPS points of each bike trip have been made available. All the GPS points have been imported by the software SUMOPy, where they have been matched with the geo referenced road network of Bologna. This network has been derived from the OpenStreetMap (OSM) database and therefore, each edge contains information such as number of lanes, length, width, permissions and so on; intersections are modeled in great detail, as well. The study area covers a surface of approximately $140 \mathrm{~km}^{2}$. Figure 2 shows the road network, overlapped with the GPS points and the zones used for the origin to destination matrix estimation. These zones derive from the 2001 census, where the Municipality of Bologna was subdivided into 125 zones, with an average surface of $0.35 \mathrm{~km}^{2}$ in the historical center and of $1.2 \mathrm{~km}^{2}$ in the suburbs. Before the GPS point importation phase, many traces have been filtered out for the three principal reasons: 1) Trips starting or ending outside of the study area. 2) Trial trips carried out before the launch of the FFBSS, identified by particular bike's IDs. 3) Trips starting out of the study period - some trips were affected by clock synchronization errors. During this cleaning phase, 7,795 incorrect traces have been deleted, which equals to $1 \%$ of the total traces provided $(915,116)$. While importing the traces in SUMOPy, further filtering on distance, time and speed is needed, too short trips in terms of both, time and length as the crow flies have been deleted. In particular, only trips with at least 30 $\mathrm{s}$ of duration and $100 \mathrm{~m}$ of direct length (geometrical distance between starting and ending points) have been taken in consideration.

These inadmissible traces are probably due to either mechanical bike-problems, which occurred after starting the trip or recording problem of the device. With this phase, the trips with incorrect information, probably due to signal problems, were identified and deleted, as well. The trace import required almost ten hours on an i7 processor and a 7200 RPM ATA disk drive. After the import, 743,459 traces remained - which equals $81 \%$ of the model provided trips. Trips are more concentrated

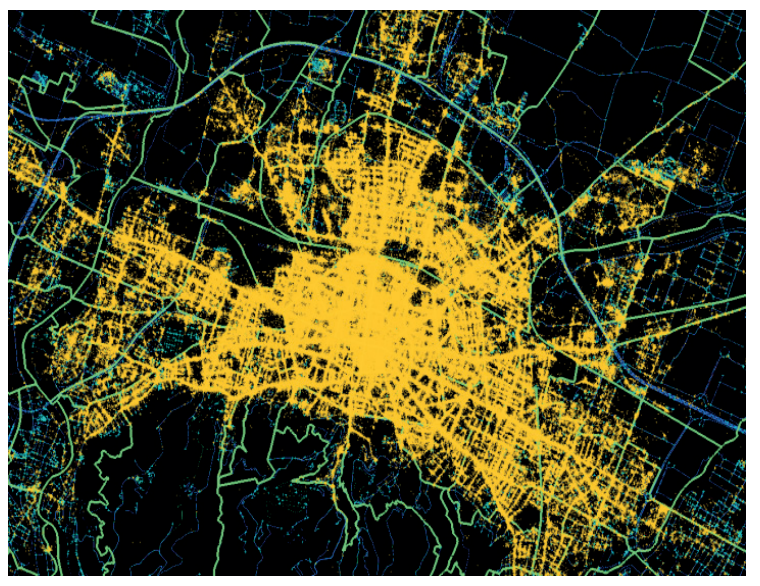

(b)

Figure 2 Bologna network imported in SUMOPy with the zoning (a) and GPS traces (b) 
Table 1 Trips duration, length and speed for different weekdays (the percentage of variation compared to weekday values are reported in brackets)

\begin{tabular}{cccc}
\hline & Av. duration $[\mathrm{s}]$ & Av. direct length $[\mathrm{m}]$ & Av. speed $[\mathrm{km} / \mathrm{h}]$ \\
\hline Weekdays & 725 & 1541 & 8.03 \\
Saturday & $804(+10.9 \%)$ & $1624(+5.4 \%)$ & $7.70(-4.1 \%)$ \\
Sunday & $824(+13.7 \%)$ & $1684(+9.3 \%)$ & $7.81(-2.7 \%)$ \\
\hline
\end{tabular}

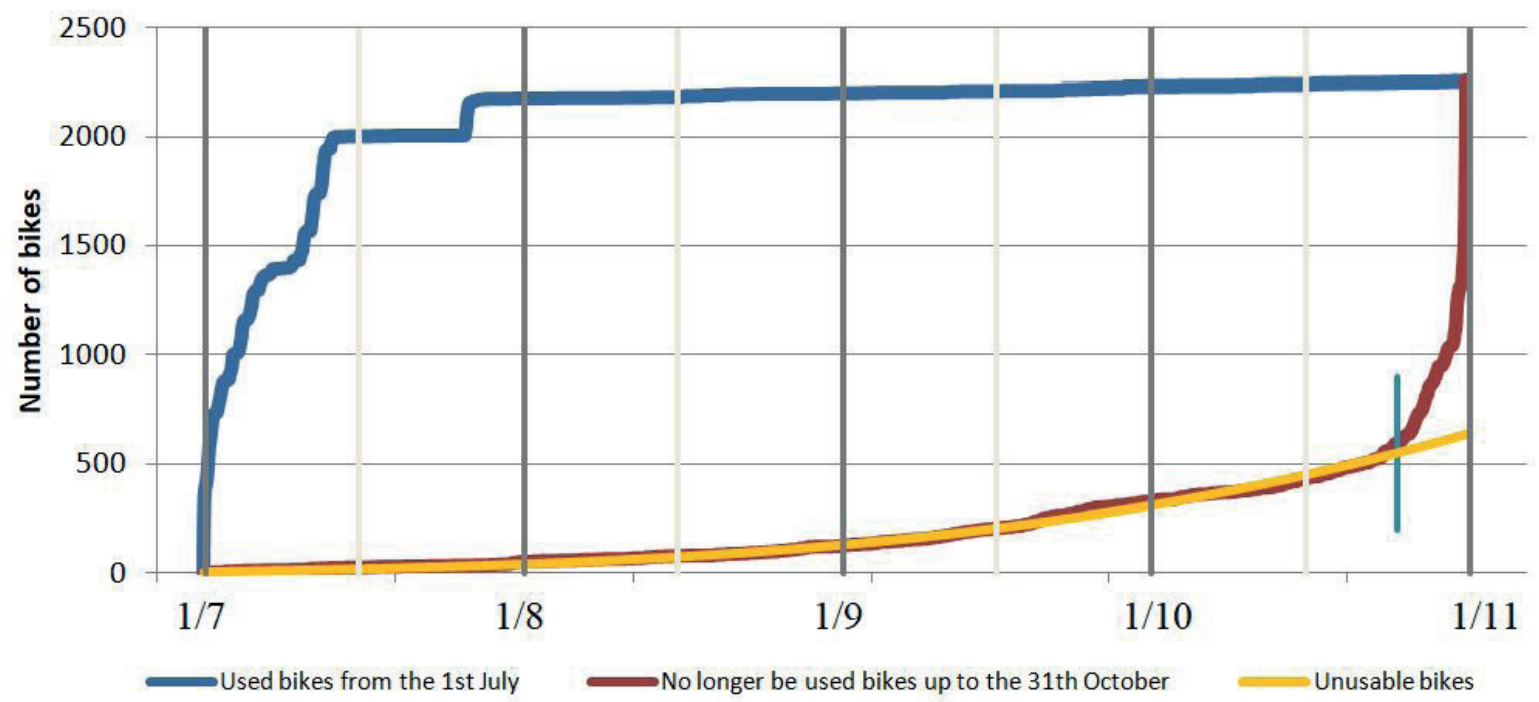

Figure 3 Bike availability analysis: provided vs. unusable bikes

in the historic center: these trips have been compared to manual cyclist surveys performed in the city of Bologna by DICAM-Transport, University of Bologna since 2009 (Bicycle survey in Bologna [35]). In particular, since 2018; the FFBSS bicycles have been observed by the manual counts, as well, at 23 key locations. Survey results show that the share of the FFBSS bikes is on average $7 \%$ of all counted bikes in central zone and $1.5 \%$ in peripheral zones, observed from 4 counter locations. From the first data analysis, it emerges that trips carried out during the weekdays are shorter than trips carried out during the weekends in terms of both time and length, which means that work-day trips are generally faster(see Table 1). Clearly, the length as the crow flies has been evaluated with the provided data, which contains only information on the trip start and end-points. Moreover, it has been proven that the one-parametric Rayleigh probability distribution (RPD) function [36] fits well with the distribution of durations of the Mobike trips, where $\sigma$ is the distribution parameter that must be calibrated. After normalizing the distribution, while considering minutes as the unit of measurement, the $\sigma$-parameter has been calibrated by maximizing the goodness of fit with the RPD.

The goodness of fit has been evaluated with the regression method by calculating the $\mathrm{R}^{2}$ value obtained by matching the histogram values of the normalized distribution of trip durations with the respective values of the RPD. For the case study, the optimal of $\sigma=8.5$ maximizes $R^{2}$ at $R^{2}=0.98$.

\section{Bike availability}

In order to investigate the FFBSS demand patterns, the first step has been to identify the FFBSS supply in terms of the bike-availability trend during the study period. As anticipated, the Mobike company promised 2,200 bikes by the end of the 2018. However, it is important to know when exactly these bikes have been put into service. For this reason, the bike ID of each trip in the data sample has been taken into consideration: 1) to evaluate when bikes have entered the system (observing when they registered their first trip) and 2) to detect when some bikes left the system (observing when bikes registered their last trip), within the study period. Figure 3 summarizes the bike supply during the study period. The two main curves represent: 1) The total number of bikes already used up to a certain time (used bikes); 2) the total number of bikes, which are no longer used, from a specific time up to the end of the study period (these are bikes considered lost). The difference between these two curves represents the available number of bikes at a certain time. Figure 3 shows that 2,200 bikes have been gradually introduced (blue curve), while the number of unusable bikes - which can be considered lost bikes - increased exponentially during the study period.

From the statistical analysis of the bike-usage frequency, the average inactive time of bikes is 7.30 hours. Moreover, the maximum inactive time between the two successive bike-usages has been 1,600 hours 


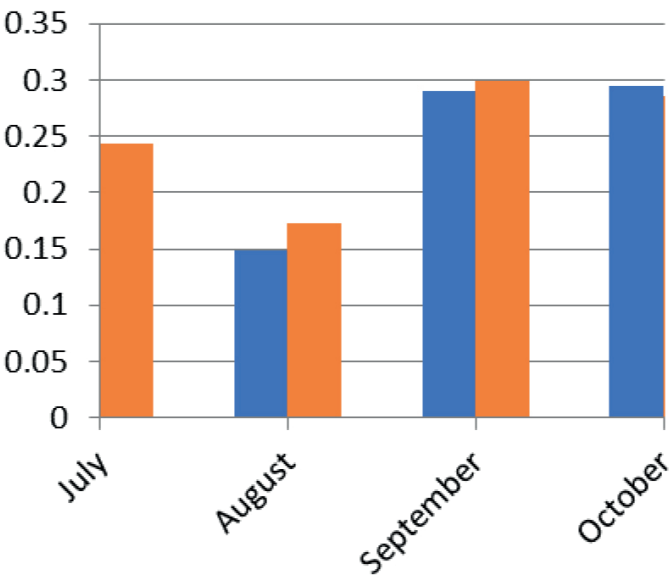

All bikes Mobike

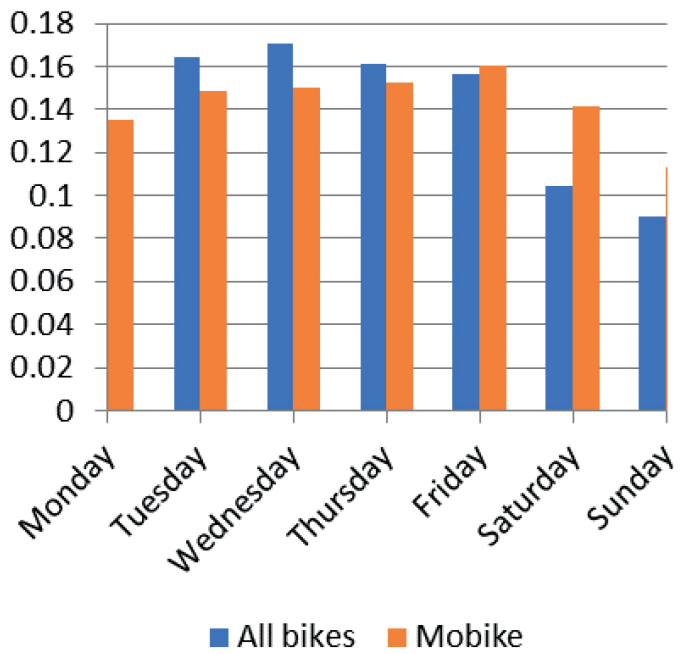

(b)

Figure 4 Comparison between the relative frequency of all bikes passing from the section of the Bologna bike network in "Viale Ercolani" and the Mobike trips per available bike for each month (a), week day (b)

(about 67 days). By considering the $99.5^{\text {th }}$ percentile of the inactive time distribution (163 hours), a timethreshold can be set (see Figure 3, vertical line in light blue), after which bikes will be probably used the next time only after the study period. Therefore, bikes, which recorded their last trip before this threshold are probably lost. The curve representing the number of bikes no longer used within the study period up to the time-threshold has been interpolated with a thirddegree polynomial trend line. With this interpolation, an R-square of more than 0.99 has been obtained. Assuming that the lost-bike trend remains the same for the next few days after the time threshold, the interpolating curve is extended up to the end of the study period. Based on this assumption, 640 bikes were lost within these 4 months. The lost bike curve shows an almost exponential growth. This means that, after all the bikes have been introduced, the number of available bikes decreases exponentially with time, which may be a deep concern for the operator.

\section{Temporal analysis of the FFBSS demand}

Keeping in mind the fact that the bike availability decreases exponentially in time, an analysis of the temporal distribution of all trips has been performed. Looking at a monthly aggregation of trip numbers per month (red columns in Figure 4a), a contraction of trips is clearly visible during the holiday period in August. This is true for all the transport modes, as transport demand is generally reduced during holidays: people carry out less trips during this period. The most likely reason is that many people leave Bologna for vacation there were in average $38 \%$ less trips per available bike per day in August. From the other hand, on Sunday there are on average $20 \%$ less trips per available bike with respect to the daily average in the study period (see red columns of Figure 4b), which amounts to 3.16 trips per available bike per day or 6,000 trips/day in total, without considering the bike availability effect. Surprisingly, more trips are made on Saturday with respect to Monday. This phenomenon may be due to the fact that new bike-users may have found in the FFBSS enough advantages to choose this means of transport during the week-end - especially since the cost per ride was very low ( $0.3 €$ every 30 minutes) during the study period. Moreover, this anomaly can be related to distribution of the departure times during the different week days: from Friday to Sunday, particularly for Saturday, there is a high use of the FFBSS during the night, with respect to the use of private bikes. The red line in Figure 5 shows the relative frequency distribution of the FFBSS trips during the study period; from this figure the lower use of the FFBSS for holidays emerges, particularly on Sunday and for the month of August, with a lower peak on August $15^{\text {th }}$.

In order to compare the FFBSS demand with ordinary cycle trips, results of a stationary bike counter, counting all the bike types, have been analyzed. This bike-counter is located at the "Tangenziale delle Biciclette" cycle way along the Viale Ercolani, Bologna (see Figure 1), a bikeway characterized by a high flow of cyclists [37]. Cyclists with ordinary bikes seem to show different behavior (see Figure $4 \mathrm{~b}$ ), thus confirming that FFBSS is particularly appreciated on the week-end, as on Saturdays and on Sundays there are more trips with shared bikes than trips with ordinary bikes. Another reason for the lower use of the FFBSS during work days could be that there is a shortage of FFBSS supply during the rush hours. From the other hand, Figure 4a does not show significant differences between the use of FFBSS bikes and the ordinary bikes. The trend of the FFBSS usage during the study period is represented day by day in Figure 5. 


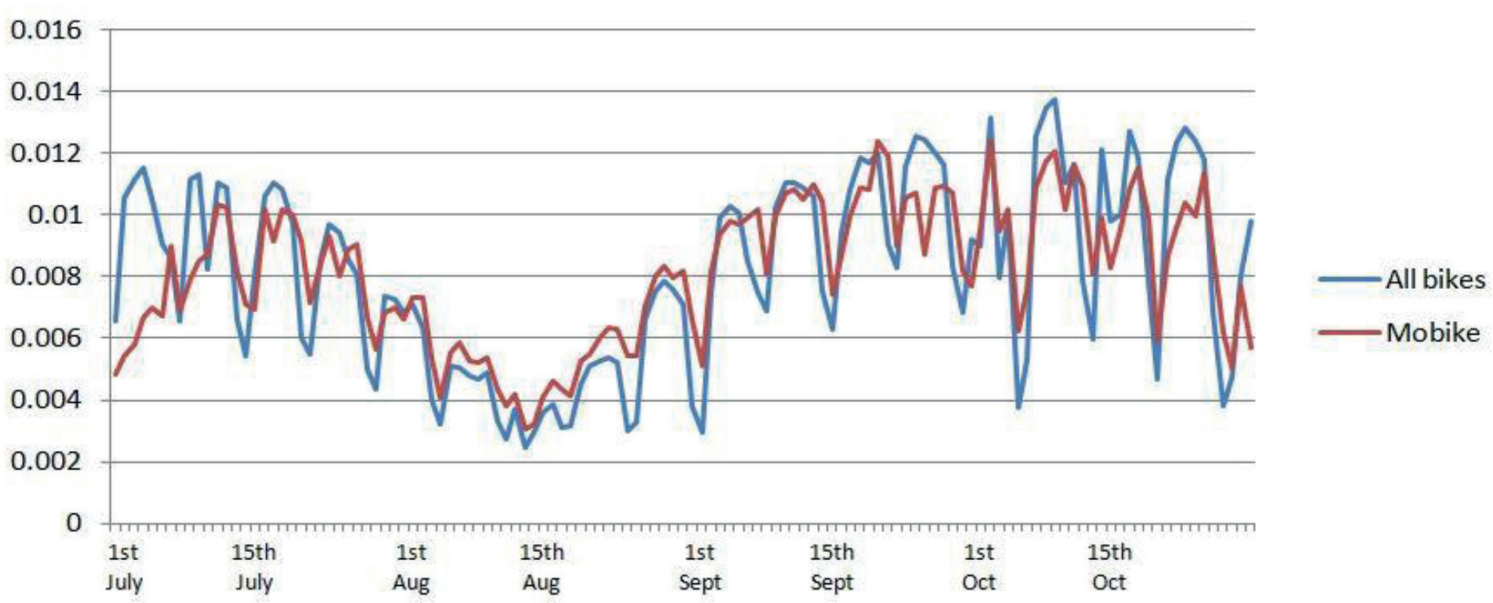

Figure 5 Comparison between the relative frequency of all the bikes passing from the section of the Bologna bike network in "Viale Ercolani" and the number of Mobike trips per available bike for each day

\section{A new predictive model for the FFBSS demand}

This paragraph presents a linear regression type model to predict the daily traffic of the FFBSS in terms of trips per available-bike, depending on the type of day. In section 4 was shown that it is important to take into account a varying number of available bikes. In order to differentiate the day types, several day-attributes are included in the model: 1) Sundays (0 for MondaySaturday, 1 for Sunday), because on Sunday there is a significant demand contraction as shown in Figure 4b; 2) Holiday period (1 for August, 0 for July, September and October); 3) Average daily air-temperature; 4) Minimum daily air-temperature; 5) Maximum daily air-temperature; 6) Average daily relative humidity; 7) Average daily wind speed; 8) Maximum daily wind speed; 9) Rain (1 if it rained, 0 otherwise); 10) Storm (1 if there was a storm, 0 otherwise); 11) Fog (1 if there was fog, 0 otherwise); 12) Millimeters of rain fall. Different data sources have been used to classify the days from a meteorologically point of view [38-40]. Since the airtemperature attributes can influence the decision to make a bike-trip (e.g. whether it is too cold or too hot), these values have been transformed in an absolute difference with respect to the comfort temperature considered initially $20{ }^{\circ} \mathrm{C}$. The same procedure has been adopted for the average daily relative humidity, by considering $50 \%$ as a comfort value. A linear regression has been performed by taking the average number of daily trips per available-bike as dependent variable. The first days of July (up to the $9^{\text {th }}$ July) are not considered since not all bikes were available and the FFBSS was not at full capacity. The most significant meteorologically variables have been the average daily temperature and the millimeters of rain fall; also attributes, which characterize the days in terms of the day-type (weekday or holiday) and period (working or holiday period) have conditioned the FFBSS demand. These variables are then more deeply analyzed in order to strengthen the relation with the dependent variable: the number of daily trips per available-bike. Firstly, the comfort average daily temperature for cyclists has been estimated more precisely: as the absolute difference with the comfort temperature. Figure 6 represents the R-square variation of the analyzed model for different values of the comfort temperature, concluding that $19{ }^{\circ} \mathrm{C}$ represent the best value for the study period. This means that days with an average daily temperature of $19{ }^{\circ} \mathrm{C}$ were preferred by cyclists. In the study period, days with this average daily temperature had a variable temperature between $16{ }^{\circ} \mathrm{C}$ and $24{ }^{\circ} \mathrm{C}$. Regarding the attribute, which refers to the period (working or holiday period), it is not significant to split holidays from weekdays, especially in the summer period: this is why it has been decided to adjust this attribute based on the FFBSS user behavior. In particular, the bike-usage for both FFBSS and private bikes decreases linearly up to the main holiday day ( $15^{\text {th }}$ August), see Figure 5 and then it regrows with the same slope. In order to better reproduce the attribute referred to the period, the threshold $\mathrm{T}$ between holiday and work periods has been blunt by assigning 1 to August $15^{\text {th }}$ and

$1-\frac{1}{D} \cdot d_{i}$

to the i-th day, where $d_{i}$ is the distance to August $15^{\text {th }}$ in terms of days: this applies up to the distance $D$ to August $15^{\text {th }}$ (the other days will have 0 ), in both directions. The parameter $D$ indicates the number of days influenced by the summer period, starting from August $15^{\text {th }}$. In order to find the optimal $D$ and then to determine the impact of the summer holidays in the FFBSS demand, the same process has been used to find the comfort temperature. The variation of the analyzed model R-square with respect to $D$ shows that the optimal value for $D$ is 27 : this means that from 27 days before and after August $15^{\text {th }}$ (respectively the July $19^{\text {th }}$ and September $11^{\text {th }}$ ), the number of the FFBSS trips starts decreasing linearly until it reaches the level of August $15^{\text {th }}$. The new linear regression with the daily average number of trips per 


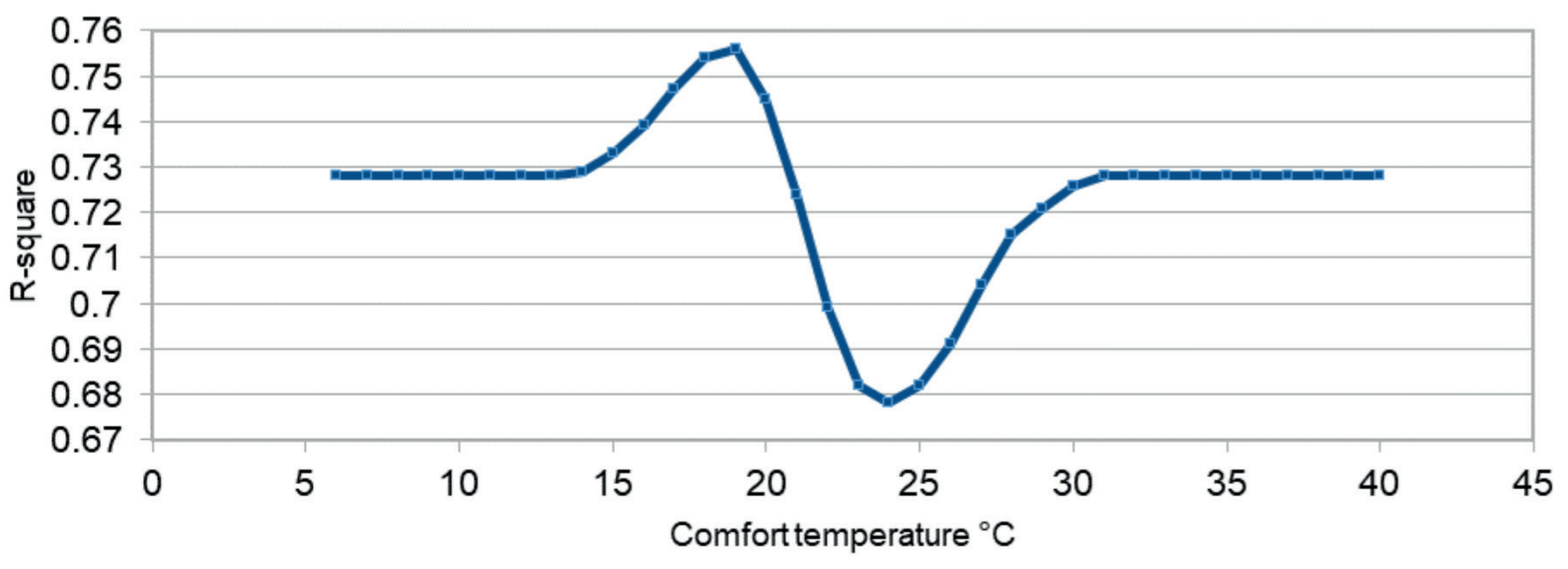

Figure 6 -square variation with respect to the comfort temperature

Table 2 Results of the linear regression

\begin{tabular}{cccccccc}
\hline Code & Attribute & Coefficient & Standard error & Stat. t & \multicolumn{1}{c}{$\mathrm{P}>|\mathrm{z}|$} & Average & Average variation \\
\hline $\mathrm{C}$ & Constant & 4.258 & 0.0879 & 48.449 & $2.99 \mathrm{E}-57$ & $/$ & $/$ \\
IS & Sunday [dummy] & -0.920 & 0.1287 & -7.149 & $5.52 \mathrm{E}-10$ & 0.146 & 0.134 \\
$\mathrm{IH}$ & Holiday period & -2.292 & 0.1739 & -13.177 & $5.55 \mathrm{E}-21$ & 0.220 & 0.504 \\
$\mathrm{DT}$ & $\Delta \mathrm{T}\left[{ }^{\circ} \mathrm{C}\right]$ & -0.0490 & 0.0200 & -2.451 & 0.016635 & 5.459 & 0.267 \\
$\mathrm{MR}$ & Rain fell $[\mathrm{mm}]$ & -0.0512 & 0.0075 & -6.81239 & $2.32 \mathrm{E}-09$ & 2.829 & 0.144 \\
\hline
\end{tabular}

Table 3 Attributes' significance

\begin{tabular}{cccccc}
\hline Code & Attribute & Mean & Standard deviation & Range & Max. variation of $N / N B$ \\
\hline IS & Sunday [dummy] & 0.146 & 0.355 & $0-1$ & -0.920 \\
IH & Holiday period & 0.220 & 0.315 & $0-1$ & -2.292 \\
DT & $\Delta \mathrm{T}\left[{ }^{\circ} \mathrm{C}\right]$ & 5.459 & 3.244 & $0-12.94$ & -0.634 \\
MR & Rain fell [mm] & 2.829 & 5.429 & $0-35$ & -1.791 \\
\hline
\end{tabular}

available-bike as a dependent variable is summarized in Table 2, reporting the coefficients for the above illustrated attributes, using a comfort temperature of $19{ }^{\circ} \mathrm{C}$ and a $D$-value of 27 days. Moreover, only the study period after August $15^{\text {th }}$ has been considered: the period before August $15^{\text {th }}$ will be used successively for the model validation. All the attribute values are statistically significant and they contribute to a similar level of variation of the dependent variable, evaluated as the average value of each attribute multiplied by the calibrated coefficients.

The constant coefficient represents the expected number of trips per available/bike in a sunny weekday with the average daily temperature of $19^{\circ} \mathrm{C}$. The other coefficients represent the decrease in daily average trips per available-bike due to different factors. In particular, on Sunday, each bike carried out on average 0.92 trips less. During the holiday period there is a consistent decrease in bike-usage up to 2.29 trips per available-bike less, in days closer to August $15^{\text {th }}$. On the other hand, the meteorological conditions influence the average number of trips per day per bike, as well: each degree Celsius of difference between the average daily temperature and the comfort temperature and each millimeter of rain fall reduce bike usage by 0.05 trips per available bike.

Considering this linear regression, it is possible to predict the total number of trips carried out by the FFBSS by means of the following expression:

$$
N=\left(\beta_{0}+\beta_{1} I S+\beta_{2} I H+\beta_{3} D T+\beta_{4} M R\right) N B,
$$

where $\beta_{i}$ is the generic coefficient of the respective day attribute $\left(\beta_{0}\right.$ is the constant coefficient) and $N B$ is the number of available bikes. To better highlight the significance of the selected attributes (showed in Table 3), it has been analyzed how much the dependent variable can vary at most by changing the respective attribute between its range of variation obtained in the case study. Considering the maximum range of each attribute, its influence on the dependent variable (considered as $N / N B$ ) is on a similar order of magnitude (approximately between 0.6 and 2.3). This means that the contribution of all used attributes to the demand estimation can be considered significant. In order to validate the model, Equation (2) has been applied to the data sample between the $9^{\text {th }}$ July - when $91 \%$ of the total FFBSS supply was already provided - and the $15^{\text {th }}$ August. The number of simulated daily trips has been 


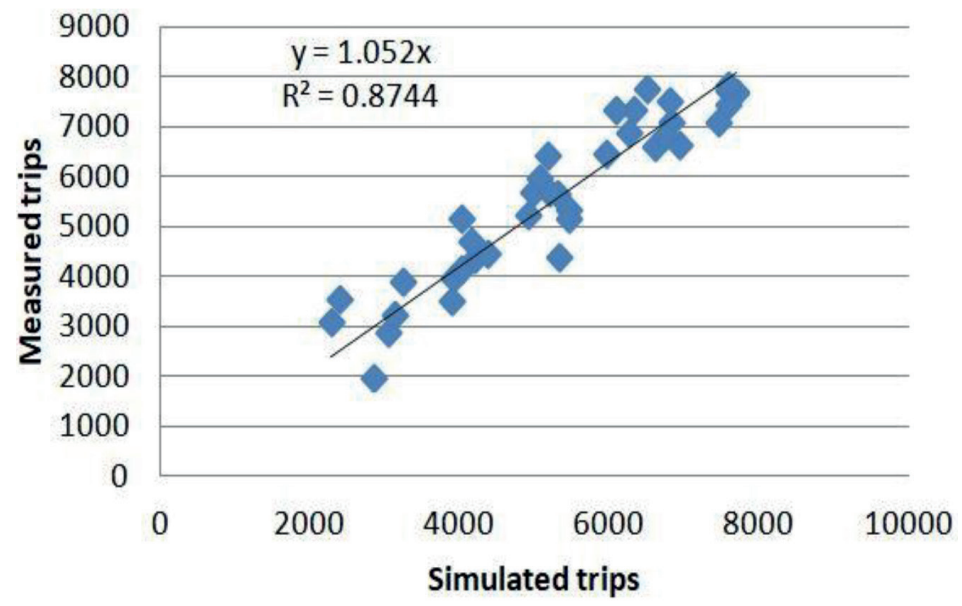

Figure 7 Modelled trips (see Equation (2)) versus measured daily number of trips with regression line

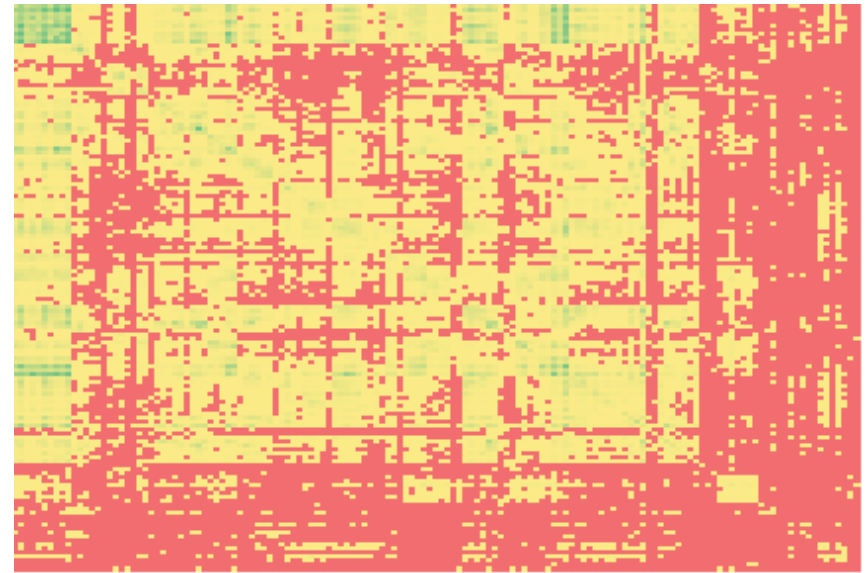

Figure 8 Origin to destination matrix

calculated and then compared with the measured ones (Figure 7), showing an R-square of 0.87 and a slope close to one.

\section{Spatial analysis of the FFBSS demand}

Based on the zoning of the 2001 population census, see Figure 2, an origin to destination trip-analysis has been carried out. In particular, an origin to destination matrix for the trips during the study period has been built by identifying the origin and destination zones of each trip from their respective locations of start and end points. The FFBSS operational area covers 144 zones (125 in the Municipality of Bologna and 19 in its province). Figure 8 shows the resulting origin to destination matrix, where each element has been colored relatively to the cell value, from red ( 0 trips $)$ to green (greater than 2,139 trips). From this dataaggregation it is possible to identify the most frequented zones (e.g. by looking for rows and columns with greener values). In particular, there are many large values of the matrix in its diagonal, which means that many trips are intra-zonal and therefore of a short distance. In order to better visualize the busiest zones, Figure 9 shows all zones colored based on the sum of departures and arrivals, together with Mobike's operational area. The number of departures and arrivals in each zone can differ only if bike-reallocation process was effected in the respective zone: in Bologna, 16,000 reallocations have been performed in the study period - on average 140 bikes/day - from the suburb to the central zones. The number of bikes reallocated by the Mobike company has been evaluated by observing how many times bikes finish their trips in one zone and start the following trip in a different zone. Figure 9 highlights that the majority of trips has been carried out in the central zone, in particular in the proximity of the bus and train station, the University quarter and the center's main attractors: the central square "Piazza Maggiore" and the famous historical tower "Torre degli Asinelli". Figure 10 shows how trip departures are concentrated in certain locations. From this figure, it is also possible to observe that the user preferences in terms of the trip 


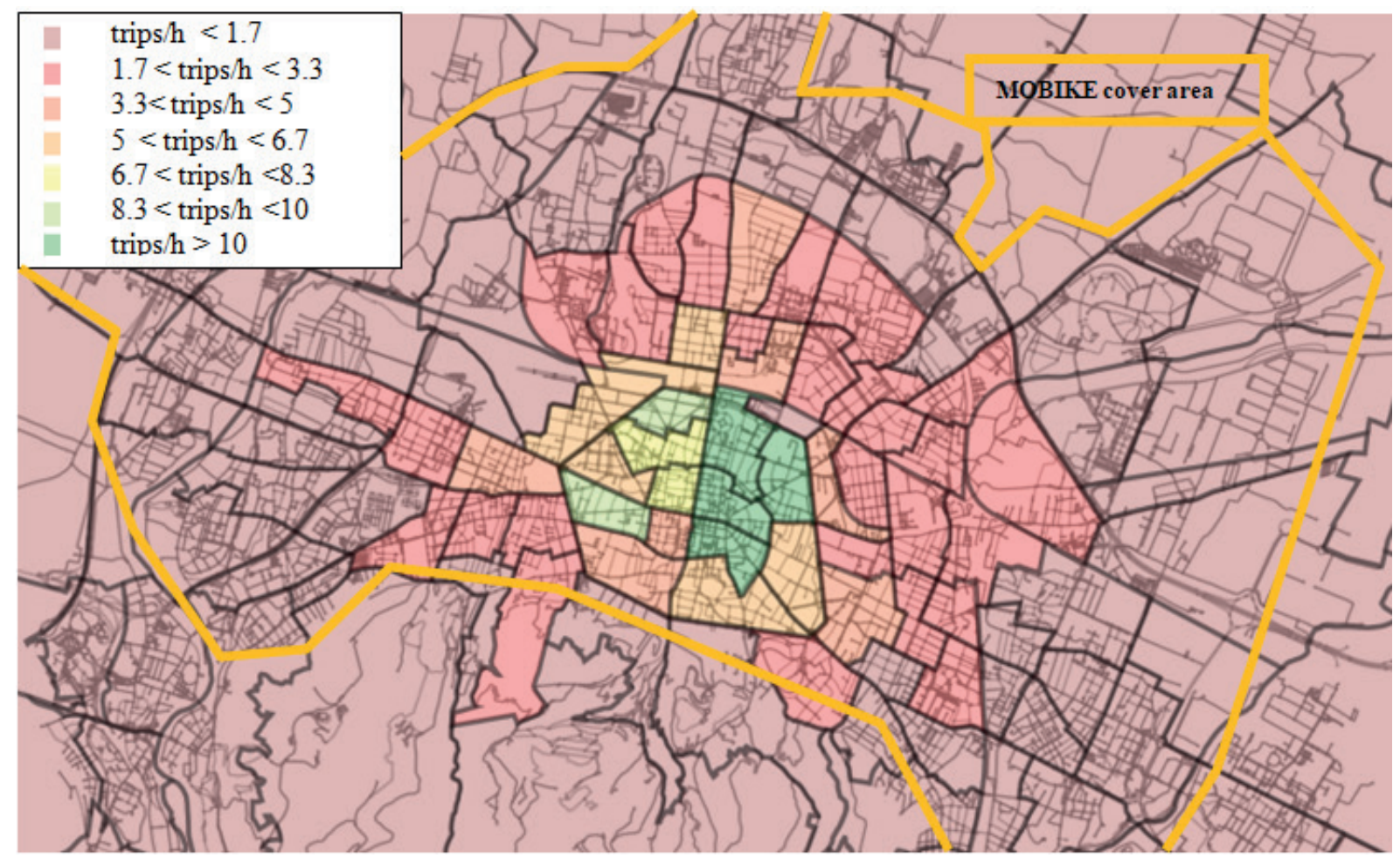

Figure 9 Spatial distribution of the average number of FFBSS trips per hour in the study period
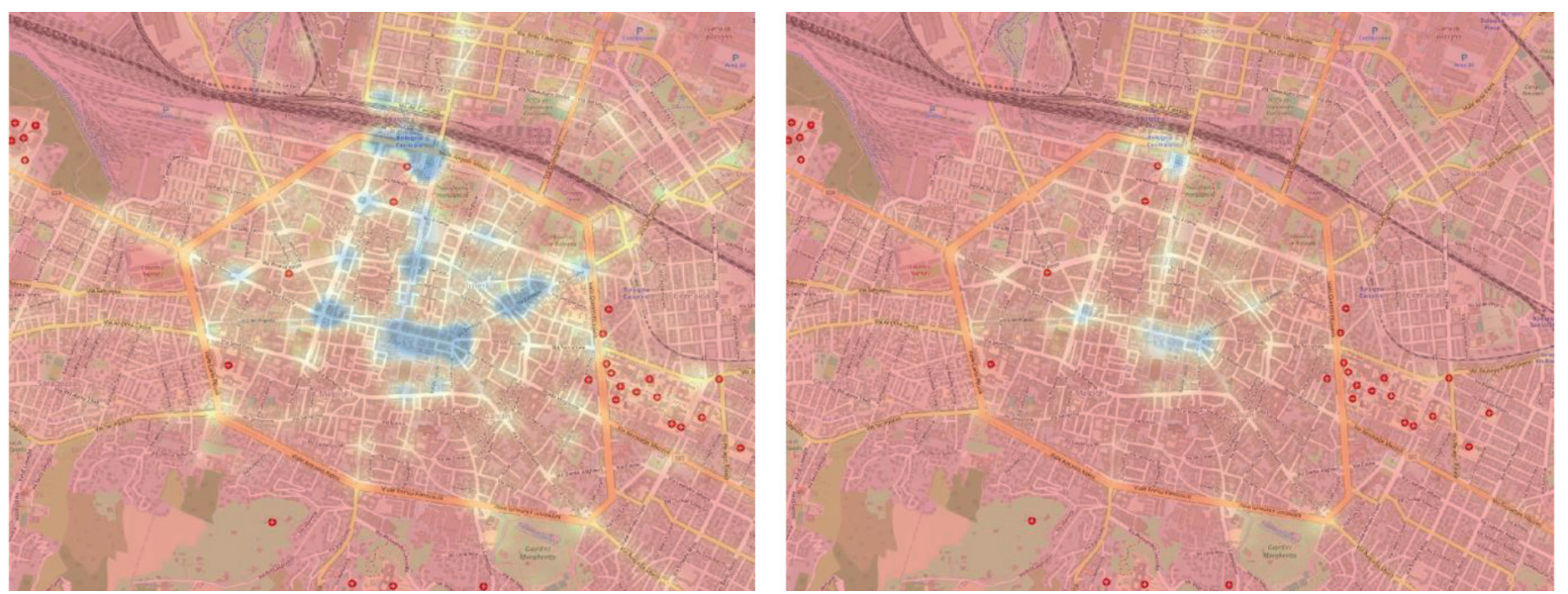

Figure 10 Heatmap of trip departures: during the working days (left) and during the week end (right), with the same representative scale

departure location do not considerably change from working days to the week end.

Moving from the central zone to the suburban zones, trips seem to decrease gradually. It can be shown that this decrease in activity is correlated with the accessibility from the city center: the bike-accessibility of a zone can be determined by measuring the time needed to arrive from other zones. For example, Figure 11 shows where cyclist, starting from the city center, arrived on average while cycling up to 15 minutes.

Figure 11 has been created by elaborating the GPS data sample: only trips starting from the city center have been considered. The color value of each network edge corresponds to the average arrival time from a randomly chosen departure edge in the center. The time to reach a specific edge during the bike trip has been determined from the temporal attribute of the trip's origin/destination GPS points and by associating these points with the geometrically closest edges. Successively, for each edge the average arrival time has been calculated, as an average travel time of trips starting in the center and ending on its proximity.

Comparing the accessibility of Figure 11 to the Mobike departure densities in Figure 10, one can clearly see a correlation, for example the higher densities and accessibility towards the north of the center.

\section{Conclusion}

An analysis of the first four months - from 1st July to 31th October - of the first and only FFBSS activity in 


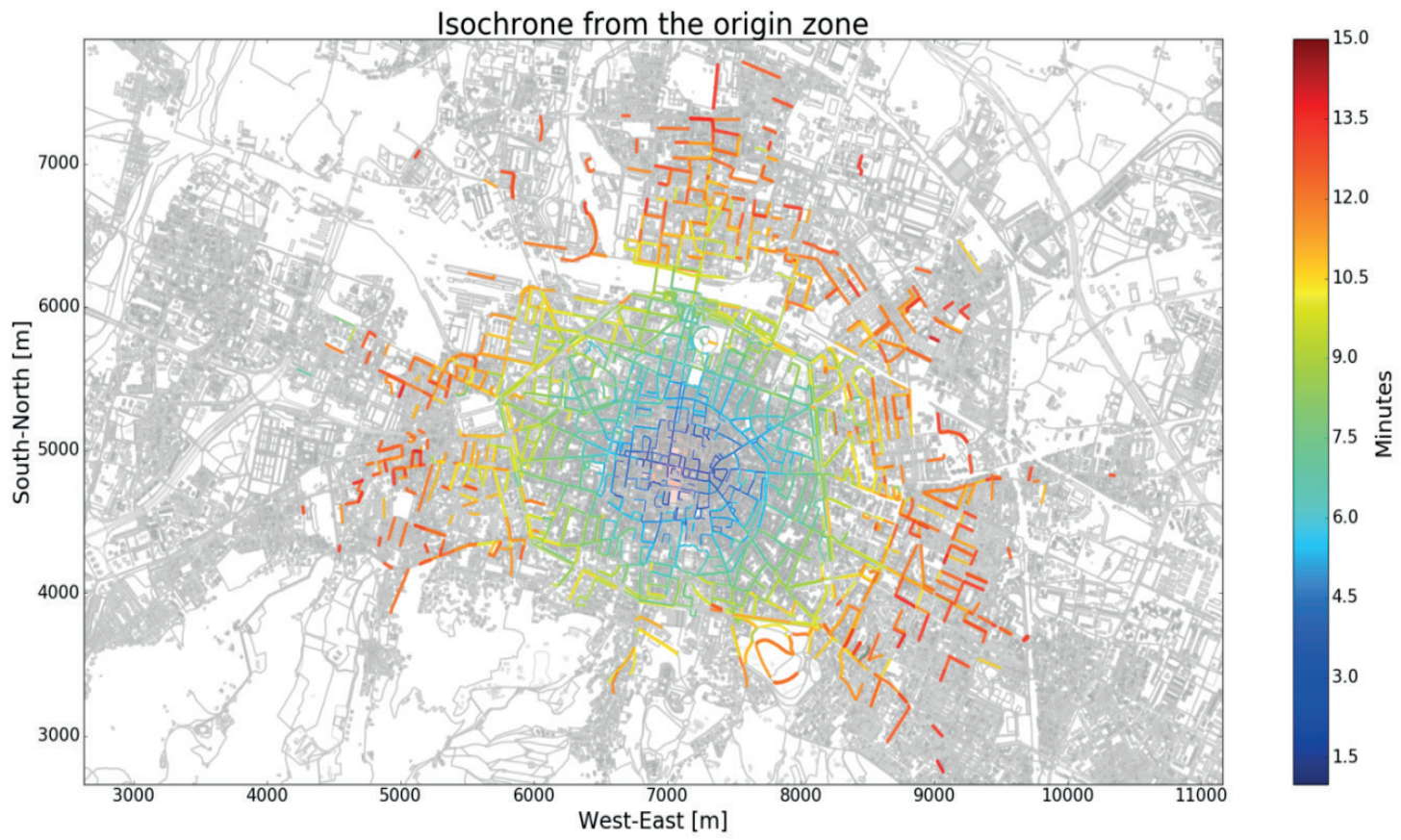

Figure 11 Isochrones from the city centre (0 to 15 minutes)

Bologna has been performed in order to characterize and interpret the FFBSS supply and usage. In particular, based on the available GPS data, a spatial and temporal analysis of the FFBSS demand has been performed. Since the FFBSS demand is not yet widely studied in literature, this research sheds some light on the supply and demand side of FFBSS, which may help in the planning and operation of such systems. For the present case study, the share of time FFBSS bikes are in use amounts to only $2.77 \%$ - which corresponds to about 40 minutes per day. Trip durations are on average 12 minutes, distributed with a RPD and equal to 8.5. A bike availability analysis shows that bikes have been put into service gradually during the first two months. The number of lost or unusable bikes increases exponentially with time: 640 of 2,200 bikes were lost in the first four months of the Mobike activity. Those bikes were probably stolen, faulty, under repair or left in unreachable places. This fact must obviously be of a great concern to the FFBSS operator, suggesting the necessity to improve bike management strategies.

On the demand side, a temporal analysis shows that, for each weekday, the FFBSS user behavior, in terms of number of trips per available bike, seems to be constant, whereas on Sunday there is a demand contraction, but this reduction in trips is less pronounced compared with trips made by privately owned bikes. In fact, the FFBSS trips do not seem to follow the ordinary temporal distribution of private bicycle trips because of the particularities of the service that are also its strength: in contrast with trips made by owned bikes, the use of FFBSS means not to worry about a bike theft and meteorological conditions; e.g. taking the bike in the morning does not oblige clients to use it for the return trip, as well, in the case it rains. For this reason, the greatest bike-usage in the week-end periods with respect to private bike trips, would suggest that in these days there are either new bike users or there is a shift from the private to shared bikes. On the other hand, during the weekdays, especially in peak hours, FFBSS supply is not sufficient to satisfy the entire demand, probably because of the spatial bike-availability problem. Based on the available number of bikes for each day of the study period, a new predictive model has been calibrated in order to estimate the average daily trips per available bike in function of the day type and weather conditions. Firstly, the average daily comfort temperature of $19{ }^{\circ} \mathrm{C}$ has been estimated as the most favorable temperature for cyclists. Over the observation period between $19^{\text {th }}$ of July and $11^{\text {th }}$ of September, demand declined linearly with a minimum at the $15^{\text {th }}$ of August. From this day on, demand increases again linearly and in symmetry to the previous decline. These results are useful in order to quantify the temperature attribute and the holiday period attribute. Once the day-attributes are fixed, a demand-prediction model has been calibrated with trips after the $15^{\text {th }}$ of August and validated successfully with others trips - starting from the $9^{\text {th }}$ of July, when $91 \%$ of the total FFBSS supply was already provided. Results show an R-square between simulated and measured trips of 0.87 . The attributes that are significant have been: 1 ) the difference between the average daily temperature and the comfort temperature; 2) the millimeters of rain fall; 3) a dummy variable indicating whether the day is a Sunday or not; 4) a period-attribute that distinguishes the holiday period from the work period.

Successively, an aggregate spatial analysis shows that trips are more concentrated in the central zone of Bologna and in particular in the surroundings of the main railway station. Trip density decreases towards 
the suburbs of Bologna. Indeed, it has been shown that the FFBSS usage decreases as the travel time to the city center increases. This means that the accessibility to the city center appears an important spatial attribute. Moreover, many trips in the case study are intra-zonal and they are characterized by short distances.

Further research can take inspiration from this work, since this topic is not fully understood; for instance, the demand prediction method could include zones (as used by Chen et al. [16]) to estimate the entire origin to destination matrix. Moreover, it would be interesting to evaluate the model transferability in terms of both time (time-period of the study) and space (other cities). The present work could also be integrated in an optimization problem that finds the best bike re-allocate strategy, by joining the predictive demand information with a real time spatial bike-distribution. In particular, if a zone has a frequent bike use, it does not necessarily mean that it needs more bikes during the reallocation process (in certain zones daily trips can balance themselves). In conclusion, this work should help to better understand the supply and demand of the FFBSS and can give the useful information to improve their future deployment and management.

\section{Acknowledgements}

We are grateful to SRM Bologna srl for providing the GPS data of the Mobike service of Bologna.

\section{References}

[1] Eurobarometer: special eurobarometer 422a "Quality of transport". Wave EB82.2 - TNS opinion social. European Commission, Brussels, Belgium [online] [accessed 2021-09-01]. 2014. Available from: https://ec.europa.eu/ commfrontoffice/publicopinion/archives/ebs/ebs_422a_en.pdf

[2] PUCHER, J., BUEHLER, B., SEINEN, M. Bicycling renaissance in North America? An update and re-appraisal of cycling trends and policies. Transportation Research Part A: Policy and Practice [online]. 2011, 45(6), p. 451475. ISSN 0965-8564. Available from: https://doi.org/10.1016/j.tra.2011.03.001

[3] RUPI, F., POLIZIANI, C., SCHWEIZER, J. Data-driven bicycle network analysis based on traditional counting methods and GPS traces from smartphone. ISPRS International Journal of Geo-Information [online]. 2019, 8(8), 322. eISSN 2220-9964. Available from: https://doi.org/10.3390/ijgi8080322

[4] Cycling - statistics facts - Statista, the statistics portal [online] [accessed 2021-09-01]. 2018. Available from: http://www.statista.com/t

[5] CAGGIANI, L., CAMPOREALE, R., OTTOMANELLI, M. A dynamic clustering method for relocation process in free-floating vehicle sharing systems. Transportation Research Procedia [online]. 2017, 27, p. 278-285. ISSN 2352-1465. Available from: https://doi.org/10.1016/j.trpro.2017.12.146

[6] FRICKER, C., GAST, N. Incentives and redistribution in homogeneous bike-sharing system with stations of finite capacity. EURO Journal on Transportation and Logistics [online]. 2016, 5(3), p. 261-291. ISSN 2192-4376. Available from: https://doi.org/10.1007/s13676-014-0053-5

[7] LIU, Y., SZETO, W. Y., HO, S. C. A static free-floating bike repositioning problem with multiple heterogeneous vehicles, multiple depots and multiple visits. Transportation Research Part C: Emerging Technologies [online]. 2018, 92, p. 208-242. ISSN 0968-090X. Available from: https://doi.org/10.1016/j.trc.2018.02.008

[8] PAL, A., ZHANG, Y. Free-floating bike sharing: solving real-life large-scale static rebalancing problems. Transportation Research Part C: Emerging Technologies [online]. 2017, 80, p. 92-116. ISSN 0968-090X. Available from: https://doi.org/10.1016/j.trc.2017.03.016

[9] CAGGIANI, L., CAMPOREALE, R., OTTOMANELLI, M., SZETO, W. Y. A modeling framework for the dynamic management of free-floating bike-sharing systems. Transportation Research Part C: Emerging Technologies [online]. 2018, 87, p. 159-182. ISSN 0968-090X. Available from: https://doi.org/10.1016/j.trc.2018.01.001

[10] TIAN, Z., ZHOU, J., WANG, M. Dynamic evolution of demand fluctuation in bike-sharing systems for green travel. Journal of Cleaner Production [online]. 2019, 231, p. 1364-1374. ISSN 0959-6526. Available from: https://doi.org/10.1016/j.jclepro.2019.05.065

[11] XU, C., JI, J., LIU, P. The station-free sharing bike demand forecasting with a deep learning approach and large-scale datasets. Transportation Research Part C: Emerging Technologies [online]. 2018, 95, p. 47-60. ISSN 0968-090X. Available from: https://doi.org/10.1016/j.trc.2018.07.013

[12] ASHQAR, H. I., ELHENAWY, M., RAKHA, H. A., ALMANNAA, M., HOUSE, L. Network and station-level bikesharing system prediction: a San Francisco bay area case study. Journal of Intelligent Transportation Systems [online]. 2021, latest articles. ISSN 1547-2450, eISSN 1547-2442. Available from: https://doi.org/10.1080/15472 450.2021.1948412

[13] DELL'AMICO, M., IORI, M., NOVELLANI, S., SUBRAMANIAN, A. The bike sharing rebalancing problem with stochastic demands. Transportation Research Part B: Methodological [online]. 2018, 118, p. 362-380. ISSN 0191-2615. Available from: https://doi.org/10.1016/j.trb.2018.10.015 
[14] NEGAHBAN, A. Simulation-based estimation of the real demand in bike-sharing systems in the presence of censoring. European Journal of Operational Research [online]. 2019, 277(1), p. 317-332. ISSN 0377-2217. Available from: https://doi.org/10.1016/j.ejor.2019.02.013

[15] PAN, Y., ZHENG, R. C., ZHANG, J., YAO, X. Predicting bike sharing demand using recurrent neural networks. Procedia Computer Science [online]. 2019, 147, p. 562-566. ISSN 1877-0509. Available from: https://doi. org/10.1016/j.procs.2019.01.217

[16] CHEN, J., ZHANG, Y., ZHANG, R., CHENG, X., YAN, F. Analyzing users' attitudes and behavior of free-floating bike sharing: an investigating of Nanjing. Transportation Research Procedia [online]. 2019, 39, p. 634-645. ISSN 2352-1465. Available from: https://doi.org/10.1016/j.trpro.2019.06.065

[17] CAGGIANI, L., CAMPOREALE, R., MARINELLI, M., OTTOMANELLI, M. User satisfaction based model for resource allocation in bike-sharing systems. Transport Policy [online]. 2019, 80, p. 117-126. ISSN 0967-070X. Available from: https://doi.org/10.1016/j.tranpol.2018.03.003

[18] PFROMMER, J., WARRINGTON, J., SCHILDBACH, G., MORARI, M. Dynamic vehicle redistribution and online price incentives in shared mobility systems. IEEE Transactions in Intelligent Transportation Systems [online]. 2014, 15(4), p. 1567-1578. ISSN 1524-9050, eISSN 1558-0016. Available from: https://doi.org/10.1109/ TITS.2014.2303986

[19] BERNARDI, S., KRIZEK, K. J., RUPI, F. Quantifying the role of disturbances and speeds on separated bicycle facilities. Journal of Transport and Land Use [online]. 2016, 9(2), p. 105-119. ISSN 1938-7849. Available from: https://www.jstor.org/stable/26203223

[20] DU, M., CHENG, L., LI, X., TANG, F. Static rebalancing optimization with considering the collection of malfunctioning bikes in free-floating bike sharing system. Transportation Research Part E: Logistics and Transportation Review [online]. 2020, 141, 102012. ISSN 1366-5545. Available from: https://doi.org/10.1016/j. tre.2020.102012

[21] USAMA, M., SHEN, Y., ZAHOOR, O. A free-floating bike repositioning problem with faulty bikes. Procedia Computer Science [online]. 2019, 151, p. 155-162. ISSN 1877-0509. Available from: https://doi.org/10.1016/j. procs.2019.04.024

[22] LAA, B., EMBERGER, G. Bike sharing: Regulatory options for conflicting interests - case study Vienna. Transport Policy [online]. 2020, 98, p. 148-157. ISSN 0967-070X. Available from: https://doi.org/10.1016/j. tranpol.2020.03.009

[23] LU, M., AN, K., HSU, S. C., ZHU. R. Considering user behavior in free-floating bike sharing system design: A data-informed spatial agent based model. Sustainable Cities and Society [online]. 2019, 49, 101567. ISSN 2210-6707. Available from: https://doi.org/10.1016/j.scs.2019.101567

[24] WAFIC, E. A., MOHAMED, S. M., KHANDKER, N. H. Effects of built environment and weather on bike sharing demand: a station level analysis of commercial bike sharing in Toronto. Transportation [online]. 2017, 44, p. 589-613. ISSN 0049-4488, eISSN 1572-9435. Available from: https://doi.org/10.1007/s11116-015-9669-z

[25] SUMOPy [online] [accessed 2021-09-01]. Available from: https://sumo.dlr.de/docs/Contributed/SUMOPy.html

[26] SUMO (Simulation of Urban Mobility) [online] [accessed 2021-09-01]. Available from: https://www.eclipse.org/ sumo

[27] POLIZIANI, C., RUPI, F., MBUGA, F., SCHWEIZER, J., TORTORA, C. Categorizing three active cyclist typologies by exploring patterns on a multitude of GPS crowdsourced data attributes. Research in Transportation Business Management [online]. 2021, 40, 100572. ISSN 2210-5395. Available from: https://doi.org/10.1016/j. rtbm.2020.100572

[28] SCHWEIZER, J., POLIZIANI, C., RUPI, F., MORGANO, D., MAGI, M. Building a large-scale micro-simulation transport scenario using big data. ISPRS International Journal of Geo-Information [online]. 2020, 10 (2), 165. eISSN 2220-9964. Available from: https://doi.org/10.3390/ijgi10030165

[29] Mobike [online] [accessed 2021-09-01]. Available from: https://mobike.com/global

[30] POLIZIANI, C., RUPI, F., SCHWEIZER, J. Traffic surveys and GPS traces to explore patterns in cyclist's in-motion speeds. Transportation Research Procedia. 2021, in press. ISSN 2352-1465.

[31] POLIZIANI, C., RUPI, F., SCHWEIZER, J., SARACCO, M., CAPUANO, D. Cyclist's waiting time estimation at intersections, a case study with GPS traces from Bologna. Transportation Research Procedia [online]. 2021, in press. ISSN 2352-1465.

[32] RUPI, F., SCHWEIZER, J. Evaluating cyclist patterns using GPS data from smartphones. IET Intelligent Transport Systems [online]. 2018, 12(4), p. 279-285. eISSN 1751-9578. Available from: https://doi.org/10.1049/ietits.2017.0285

[33] SCHWEIZER, J., RUPI, F., POLIZIANI, C. Estimation of link-cost function for cyclists based on stochastic optimization and GPS traces. ITE Intelligent Transport Systems [online]. 2020, 14(13), p. 1810-1814. eISSN 1751-9578. Available from: https://doi.org/10.1049/iet-its.2019.0683 
[34] SRM (Networks and Mobility Society, Bologna / Societa Reti e Mobilita, Bologna) (in Italian) [online] [accessed 2021-09-01]. Available from: http://www.srmbologna.it/?page_id=2435

[35] Bicycle survey in Bologna: detection of bicycle flows on the main cycle paths in the municipality of Bologna. Processing of the collected data and comparison with the available time series / rilevamento dei flussi di biciclette sulle principali piste ciclabili presenti nel territorio del comune di Bologna. Elaborazione dei dati raccolti e confronto con le serie storiche disponibili (in Italian) [online] [accessed 2021-09-01]. 2019. Available from: http://www.comune.bologna.it/media/files/report_fluss

[36] MAYMOM, G. Stochastic crack propagation: essential practical aspects. 1. ed. Academic Press, 2018. ISBN 9780128141915.

[37] RUPI, F., SCHWEIZER, J., POLIZIANI, C. Analysing the dynamic performances of a bicycle network with a temporal analysis of GPS traces. Case Studies on Transport Policy [online]. 2020, 8(3), p. 770-777. ISSN 2213-624X. Available from: https://doi.org/10.1016/j.cstp.2020.05.007

[38] Meteorological data - 3BMeteo [online] [accessed 2021-09-01]. Available from: https://www.3bmeteo.com/meteo/ bologna/storico

[39] Dext3r: meteorological data of the city of Bologna, Italy [online] [accessed 2021-09-01]. Available from: https://simc.arpae.it/dext3r/

[40] iLMeteo: metereological data [online] [accessed 2021-09-01]. Available from: https://www.ilmeteo.it/portale/ archivio-meteo/Bologna 